\title{
Hepatoprotective effect of methanolic extract of Monotheca buxifolia against isoniazid and rifampicin induced hepatotoxicity
}

\author{
Shabnam Javed ${ }^{1 *}$, Amna Shoaib ${ }^{2}$, Zaid Mahmood ${ }^{3}$, Saiqa Ishtiaq ${ }^{4}$ \\ ${ }^{1}$ Institute of Chemistry, University of the Punjab, Quaid-e-Azam Campus, Lahore, Pakistan \\ ${ }^{2}$ Institute of Agricultural Sciences, University of the Punjab, Quaid-e-Azam Campus, Lahore, Pakistan \\ ${ }^{3}$ Department of Chemistry, The University of Lahore, Pakistan \\ ${ }^{4}$ University College of Pharmacy, University of the Punjab, Allama Iqbal Campus, Lahore, Pakistan
}

\begin{abstract}
Received:
February 22, 2021

Accepted:

March 25, 2021

Online First:

March 27, 2021

Published:

September 21, 2021

\section{Abstract}

The objective of the present study to check free-radical-scavenging and hepatoprotective properties of methanolic extract of Monotheca buxifolia (Falc.) A. DC. aerial parts against isoniazid and rifampicin induced hepatotoxicity in male rats. Results exhibited that methanolic extract and all three sub-fractions (hexane, chloroform and ethyl acetate) of $M$. buxifolia displayed greater free-radical activity, total phenolic and flavonoid content. However, ethyl-acetate followed by chloroform sub fractions showed the better total phenolic and total flavonoid content. To assess hepatoprotective activity of methanolic extract of $M$. buxifolia, four groups of the rate were made. Group 1 served as a control, group 2 served as hepatotoxic group (isoniazid and rifampicin orally each $50 \mathrm{mg} / \mathrm{kg}$ ), group 3 served as standard group received silymarin $(200 \mathrm{mg} / \mathrm{kg})$, and 4 served as extract treatment groups, received $500 \mathrm{mg} / \mathrm{kg}$ methanolic extract. The results suggested that level of liver markers (total bilirubin, alkaline phosphatases, alanine aminotransferases and aspartate aminotransferases) significantly elevated in group 2. The methanolic extract significantly prevented isoniazid-rifampicin by decreasing raised level of liver markers of Group 4, and also improved histopathological profile of liver. The results indicated the protective effect of methanolic extract of $M$. buxifolia against liver injury, which might be ascribed to presence of high level of phenolics and flavonoid along with high free-radical activity in the plant extract.
\end{abstract}

Keywords: Monotheca buxifolia, Sapotaceae, Hepatoprotective, Antioxidant, Induced liver toxicity

\section{How to cite this:}

Javed S, Shoaib A, Mahmood Z and Ishtiaq S, 2021. Hepatoprotective Effect of Methanolic Extract of Monotheca buxifolia against Isoniazid and Rifampicin Induced Hepatotoxicity. Asian J. Agric. Biol. 2021(4): 202102074. DOI: https://doi.org/10.35495/ajab.2021.02.074

This is an Open Access article distributed under the terms of the Creative Commons Attribution 3.0 License. (https://creativecommons.org/licenses/by/3.0), which permits unrestricted use, distribution, and reproduction in any medium, provided the original work is properly cited.

\section{Introduction}

Drug related liver injury is problematic issue associated with use of many medication. Isoniazid and rifampicin combination therapy is commonly used to against many diseases. Isoniazid is the primary toxin, and rifampicin potentiates its toxicity through altering kinetics of metabolites (Black et al., 1975; Mitchell et 
al., 1976). Combination of these drugs are responsible for causing lover disorders via changing mitochondrial permeability and increasing oxidative stress (Chowdhury et al., 2006). Drug-induced oxidative stress in liver also increases liver biochemical markers including alanine aminotransferase (ALT), aspartate aminotransferase (AST), alkaline phosphatase (ALP) and total bilirubin (TB) in the blood serum (Gallucci et al., 2000). The liver diseases are life threatening, while discovering harmless, effective and protective drugs can provide an optimum solution to liver diseases (Hashem et al., 2019). Many investigations showed plant-based products exhibit hepatoprotective activities, due to enrichment of antioxidants like phenolic and flavonoid content in different parts of the plants (Urrutia-Hernández et al., 2019; Khan et al., 2020).

Pakistan is enjoying a rich and diverse flora of about 6,000 plant species of medicinal values. Monotheca buxifolia (Falc.) A. DC. is eatable, evergreen, wild fruit bearing bushy tree of family Sapotaceae, is native to Pakistan, while distributed in the tropical regions of the world. In Pakistan, it is generally distributed in Balochistan (i.e., Zhob, Gorakh Hills, and Loralai) and Khyber Pakhtunkhwa (Kohat, Drosh, Chitral, and Attock Districts), and its occurrence is also recorded in tribal areas along the border of Afghanistan (Ali et al., 2020). The plant parts are extensively utilized in folk medicine against various ailments particularly in the South Asia and Middle East (Ali et al., 2020). The fruit bears digestive, laxative, vermicidal, and refrigerant properties, also used in the management of gastric, eye, and urinary tract infections mainly due to its oleanolic-acid and isoquercetin contents (Ullah et al., 2016). The other plant's parts can be used against sore throat, jaundice, gastrointestinal disorder, skin dermatitis, type II diabetes and acute cystitis (Rehman et al., 2013; Ullah et al., 2016; Ali et al., 2020). Its leaves and stem have been documented to contain high level of high antioxidant activity and enriched with diverse classes of flavonoids, phenolics and terpenoids derivatives (Rehman et al., 2013; Ali et al., 2020), which are not only anticancerous and anti-diabetic but also prevent cardiovascular diseases (Vlaisavljević et al., 2019). The phytochemical profile and strong antioxidant potential of $M$. buxifolia indicate the plant may serve as the source of hepatoprotective agent. Previously, Prince et al. (2016) and Nwidu and Teme (2018) studies described hepatoprotective effects of different parts of Leucas cephalotes, Bacopa monnieri and Lasianthera Africana, respectively and their extracts against chemical toxicity induced in mice. Likewise, Vinaykumar et al. (2020) studies revealed that methanolic fruit extract of Gardenia gummifera had noteworthy antioxidant activity due to presence of alkaloids and phenolics, while same extract also exhibited hepatoprotective activity by reducing biochemical markers of hepatic injury such as alkaline phosphatase (ALP), total protein (TP), total bilirubin (TB), serum glutamyl oxaloacetate transaminase (SGOT) and serum glutamyl pyruvate transaminase (SGPT) in mice. The current study was aimed to assess antioxidant levels in the methanolic extract and their organic sub-fractions of aerial parts (stem and leaves) of the $M$. buxifolia and to investigate the protective effect of methanolic extract of M. buxifolia against isoniazid and rifampicin induced hepatotoxicity in rats.

\section{Material and Methods}

\section{Plant material}

Aerial parts (stem and leaves) of M. buxifolia $(10 \mathrm{~kg})$ were collected in Swat, Pakistan during April 2011. A voucher specimen no. GC. Bot. Herb. 815 was deposited at "Department of Botany, GC University (Lahore, Pakistan)." Aerial parts of the plant were airdried at room temperature $\left(30 \pm 0.5^{\circ} \mathrm{C}\right)$, pulverized to a coarse powder. The plant parts $(4.20 \mathrm{~kg})$ were extracted with methanol (95\%), and resulting methanolic extract (ME) (600 g) was suspended in distilled water $(400 \mathrm{~mL})$ in a separatory funnel for partitioning with organic solvent. Hexane, chloroform and ethyl acetate to obtain fractions in these solvents. Hexane (HF), chloroform (CFF) and ethyl acetate (EAF) fractions were weighed 150, 100 and $150 \mathrm{~g}$, respectively, and kept at $4{ }^{\circ} \mathrm{C}$ for further assays.

\section{DPPH radical scavenging activity assay}

Kumarasamy et al. (2007) protocol was used to check the radical scavenging capacity of the methanolic extract (ME) and different fractions (WSF, HF, CFF and EAF) of the M. buxifolia. Briefly, each ME, HF, CFF and EAF was dissolved in 95\% ethanol (1 $\mathrm{mg} / \mathrm{mL}$ ), followed by addition of freshly prepared DPPH (1,1-diphenyl-2-picrylhydrazyl). The reaction mixture $(3 \mathrm{~mL})$ was shaken and incubated $(30 \mathrm{~min})$ at room temperature in the dark, while control was prepared without adding any extract. The samples in set of triplicates were measured for change in the absorbance at $517 \mathrm{~nm}$ on UV-visible 
spectrophotometer (HACH 4000 DU) against blank. Scavenging activity of all samples was calculated through equation.

Scavenging activity $(\%)=\left[\left(\mathrm{A}_{0}\right.\right.$ (absorbance of control $\left.)-\mathrm{A}_{1}\right) / \mathrm{A}_{0}($ absorbance of sample $\left.)\right] \times 100$

\section{Total phenolic content}

Estimation of total phenolic content in extract (ME) and different fractions (HF, CFF and EAF) of the $M$. buxifolia was conducted through Folin-Ciocalteu procedure (Slinkard and Singleton, 1977). Briefly, in the mixture of extract/fraction + Folin-Ciocalteu reagent, saturated $\mathrm{Na}_{2} \mathrm{CO}_{3}$ solution was added. After incubation of the reaction mixture in the dark for 90 min, the samples were assessed for change in the absorbance at $725 \mathrm{~nm}$ and the total phenolics were was calculated through calibration curve of gallic acid.

\section{Total flavonoid content}

Bohm and Koupai-Abyazani (1994) method was used to ascertain total flavonoid content in the methanolic extract (ME) as well as in each fraction (HF, CFF and EAF) of M. buxifolia. In brief, $50 \mathrm{mg}$ of sample was extracted repetitively with methanol $(80 \%)$, and the filtrate obtained after filtering whole solution was evaporated into dryness and weighed to a constant weight.

\section{Hepatoprotective activity}

The hepatoprotective potential of methanolic extract was carried out following the ethical principles for laboratory animal's care (Zimmerman, 1983). Twenty albino mice (male) weighing between 200-250 g were acclimatized for 3 weeks and were standard regime under experimental investigation. The animals were distributed randomly into four groups of five animals per cage. The animals in group 1 received $1 \mathrm{~mL} / \mathrm{kg}$ sterile saline orally. Group 2 consisted of rat, which received oral dosage of isoniazid (INH) and rifampicin (RMP) $(50 \mathrm{mg} / \mathrm{kg})$. Group 3 served as standard group received silymarin suspension (200 $\mathrm{mg} / \mathrm{kg}$ ). The animals in group 4 received the ME of the plant $(500 \mathrm{mg} / \mathrm{kg})+\mathrm{INH}(50 \mathrm{mg} / \mathrm{kg})+\mathrm{RMP}(50$ $\mathrm{mg} / \mathrm{kg}$ ) in distilled water. The study groups dosed once daily by oral route. The blood sample were collected after 48 hours of receiving the dose on $3^{\text {rd }}$ week, under anesthesia for evaluation of biochemical parameters. Enzymes sassy (ALP, ALT and AST) and total bilirubin test were carried out commercial kits supplied by Sigma-Aldrich Germany.

\section{Histological examination}

Forty-eight hours after last administration, the animals were anaesthetized under chloroform vapour and were dissected. A portion of liver was processed fixed in Bouin solution, trimmed down to a size $3 \mathrm{~mm}$ slices, and colored with hematoxylin-eosin. For evaluation of histological alterations, these slides were observed under light microscope.

\section{Statistical analysis}

Means, standard deviations (SD) and standard error (SE) were calculated on excel. ANOVA followed by Fisher's protected least significant difference test $(\mathrm{P} \leq 0.05)$ was used to determine the significant effects $(\mathrm{P}<0.05)$ among the treatments using the SATISTIX 8.1.

\section{Results and Discussion}

During past few years, utilization of plant-based products against a number of maladies have gained momentum due to occurrence of active constituent's e.g. phenolic compounds and their flavonoid. Results revealed that methanolic extracts and its three subfractions exhibited significantly greater free-radical activity in the range of $50-60 \%$. However, the methanolic extract and its ethyl acetate sub-fraction displayed the maximum free-radical activity followed by hexane and chloroform sub-fractions. Moreover, total flavonoid content of the ethyl acetate subfraction was many fold greater (48\%) as compared to the said attribute in the methanolic extract and rest of the sub-fractions (8.0-13.0\%). Likewise, total phenolic content of the ethyl acetate sub-fraction $(90$ $\mathrm{mg}$ gallic acid equivalent/g) was significantly greater followed by 80,50 and 30 by CFF, HF and ME, respectively (Table 1). Similar to current study, Jan et al. (2013) documented substantial antioxidant activity of methanolic extracts of $M$. buxifolia (fruit) and its various fractions (aqueous, butanol, ethyl acetate and $n$-hexane), and they ascribed presence of high content of total phenolic and flavonoid contents may be responsible for high antioxidant potential of the plant. Likewise, Ali et al. (2020) reported significant relationship between phenolics (rutin, picatechin and catechin et.) and antioxidant activity of the $M$. buxifolia. Likewise, occurrence of many active constituents ( $\alpha$-tocopherol, serotonin, 3deoxyestradiol, cirsimaritin and ascorbyl palmitate) in bark extract of $M$. buxifolia have been linked with 


\section{Muhammad Ehsan Safdar et al.}

plant antioxidant activity. Furthermore, antioxidant, anticancer, and cardioprotective activity of the polyphenolics and flavonoids of $M$. buxifolia have been evidenced (Vlaisavljević et al., 2019). Khan et al. (2020) documented that phytoconsitutents of Monotheca plant contributed in its hepatoprotective, anti-inflammatory, antipyretic, etc. activities.

Table-1. Total phenolics, total flavonoids and Freeradical-scavenging activity of methanol extract and soluble fractions of Monotheca buxifolia.

\begin{tabular}{|l|c|c|c|}
\hline \multicolumn{1}{|c|}{$\begin{array}{c}\text { Extract/ } \\
\text { Fraction }\end{array}$} & $\begin{array}{c}\text { Total phenolic } \\
\text { content (mg gallic } \\
\text { acid equivalent/g) }\end{array}$ & $\begin{array}{c}\text { Total } \\
\text { flavonoid } \\
\text { content }(\%)\end{array}$ & $\begin{array}{c}\text { Free-radical- } \\
\text { scavenging activity } \\
(\%)\end{array}$ \\
\hline $\begin{array}{l}\text { Methanolic } \\
\text { extract }\end{array}$ & $30^{\mathrm{d}} \pm 2.60$ & $7.50^{\mathrm{c}} \pm 0.07$ & $61.80^{\mathrm{ab}} \pm 0.20$ \\
\hline $\begin{array}{l}\text { Hexane sub- } \\
\text { fraction }\end{array}$ & $50^{\mathrm{c}} \pm 5.60$ & $8.01^{\mathrm{c}} \pm 0.80$ & $52.60^{\mathrm{c}} \pm 5.60$ \\
\hline $\begin{array}{l}\text { Chloroform } \\
\text { sub-fraction }\end{array}$ & $80^{\mathrm{ab}} \pm 2.30$ & $13.40^{\mathrm{b}} \pm 1.20$ & $50.20^{\mathrm{cd}} \pm 2.30^{\mathrm{c}}$ \\
\hline $\begin{array}{l}\text { Ethyl acetate } \\
\text { sub-fraction }\end{array}$ & $90^{\mathrm{a}} \pm 1.10$ & $48.0^{\mathrm{a}} \pm 2.30$ & $58.20^{\mathrm{a}} \pm 0.60$ \\
\hline
\end{tabular}

Each value in the table is represented as mean $\pm \mathrm{SD}$ (n $=3$ ). Values in the same column followed by a different letter (a-d) are significantly different $(\mathrm{P}<$ $0.05)$.

In an attempt to check hepatoprotective potential of methanolic extract of $M$. buxifolia, isoniazid (INH) and rifampicin (RMP) treated rats were used. INH and RMP are potent hepatotoxic drugs and have been utilized as standard hepatotoxic in many experimentations (Ullah et al., 2016). Results showed that total bilirubin level as well as the activity of ALT, AST, and ALP enzymes in group 2 increased to 3.50 (g/dL), 34.70 (IU/L), 67.10 (IU/L), and 47.30 (IU/L), respectively, compared to healthy control group 1 . However, in group 3 (silymarin + isoniazid + rifampicin) and 4 (methanolic extract + isoniazid + rifampicin), total bilirubin level and the activity of ALT, AST, and ALP enzymes decreased significantly $(\mathrm{P}<0.05)$. Also, based on the obtained results, the activity of AST and ALT enzymes in the test Group 3 showed a better decrease compared to other test groups (Table 2). Histopathological observations results of liver tissue of rats exhibited normal hepatic parenchyma, hepatic lobules and cords arrangement in group 1 (Figure 1A). Liver damages such as duct proliferation, necrosis, and degeneration of cytoplasmic and nuclear destruction were observed in group 2 (Figure $1 \mathrm{~B}$ ). In group 3 and 4, liver histopathological profile improved as negligible changes were observed (Figure $1 \mathrm{C}, \mathrm{D}$ ).

Significant enhancement in enzyme levels and total bilirubin in group 2 had caused cellular lesions, inflammatory cells and disorganization of hepatic tissue structure. The hepatoprotective activity of the INH and RMP might be ascribed to biochemical warning of hepatic injury due to binding of drug or its metabolite to cellular proteins making new adducts that aids in targeting immune system accompanied by generation of free radicals to hepatocyte membranes hence induced membrane and necrosis damage (Ullah et al., 2016; Tahmasebi et al., 2018). Total bilirubin and the tested liver enzymes decreased without causing major alterations in the liver function in group 3 and 4. Ullah et al. (2016) also recorded strong hepatoprotective effect of $M$. buxifolia fruit against INH and RMP induced liver toxicity in rats, these authors corroborated occurrence of isoquercetin and oleanolic acid in the plant extract could be cause of glutathione regeneration and reduction in the oxidative stress.

Table-2. Effect of Monotheca buxifolia methanol extract hepatoprotective activity in rats.

\begin{tabular}{|l|c|c|c|c|}
\hline \multicolumn{1}{|c|}{ Group } & ALT(U/L) & AST(U/L) & ALP(U/L) & $\begin{array}{c}\text { Total bilirubin } \\
(\mathrm{g} / \mathrm{dL})\end{array}$ \\
\hline I: Normal saline control & $3.40^{\mathbf{c}} \pm 0.11$ & $4.90^{\mathbf{c}} \pm 0.10$ & $5.90^{\mathbf{c}} \pm 1.10$ & $0.30^{\mathbf{b}} \pm 0.17$ \\
\hline II : Isoniazid + Rifampicin (each 50 mg/kg per day) & $34.70^{\mathbf{a}} \pm 0.21$ & $67.10^{\mathbf{a}} \pm 0.12$ & $47.30^{\mathbf{a}} \pm 0.04$ & $3.50^{\mathbf{a}} \pm 0.01$ \\
\hline $\begin{array}{l}\text { III: Silymarin (200 mg/kg per day) + isoniazid and } \\
\text { rifampicin (each 50 mg/kg per day) }\end{array}$ & $2.40^{\mathbf{d}} \pm 0.42$ & $3.10^{\mathbf{d}} \pm 0.21$ & $7.84^{\mathbf{b}} \pm 2.31$ & $0.33^{\mathbf{b}} \pm 1.61$ \\
\hline $\begin{array}{l}\text { IV: } \text { Methanol extract (500 mg/kg) + Isoniazid and } \\
\text { Rifampicin (each 50 mg/kg per day) }\end{array}$ & $7.70^{\mathbf{b}} \pm 0.51$ & $11.60^{\mathbf{b}} \pm 1.30$ & $8.10^{\mathbf{b}} \pm 3.60$ & $0.21^{\mathbf{b}} \pm 0.013$ \\
\hline
\end{tabular}

Each value in the table is represented as mean $\pm \mathrm{SD}(\mathrm{n}=3)$. Values in the same column followed by a different letter $(\mathrm{a}-\mathrm{d})$ are significantly different $(\mathrm{P}<0.05)$. 


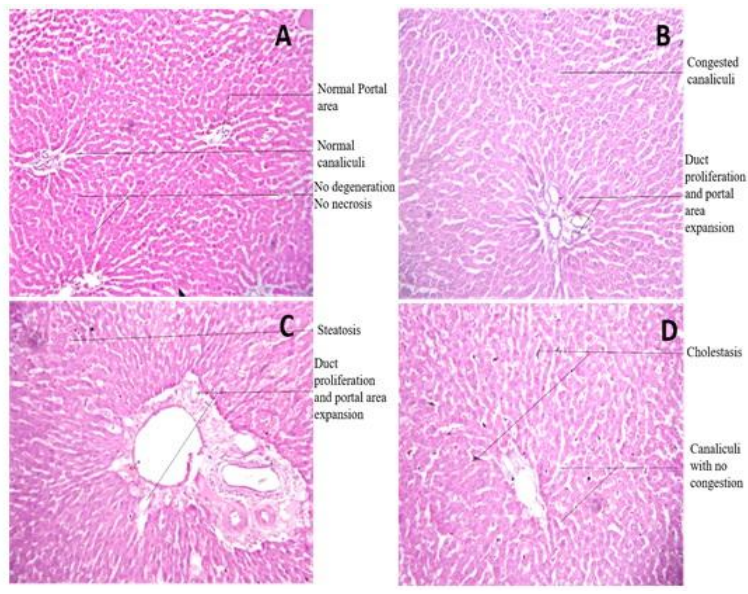

Figure-1. A: Liver sections of normal control rats showing normal hepatic cells; B: Isoniazid and rifampicin treated rats showing cellular lesions, loss of hepatic tissue structure arrangement and collection of inflammatory cells; C: Liver sections showing minimal alterations in silymarin fed-rats treated and D: methanolic extract treatment groups

Therefore, hepatoprotective effect of the methanolic extract of aerial part of $M$. buxifolia could be related to presence of natural antioxidants (total phenolics and flavonoids) that might offer high free-radicalscavenging activity in rats against the INH and RMPinduced oxidative stress.

\section{Conclusion}

It was concluded that methanolic extract of $M$. buxifolia (stem and leaves) possessed hepatoprotective potential against drug-induced hepatic harm in rats, owing to the high level of antioxidants (total phenolics and flavonoids) and free radical quenching potential of $M$. buxifolia.

\section{Acknowledgement}

The authors are grateful to the University of the Punjab, Lahore, Pakistan for funding this study.

Disclaimer: None.

Conflict of Interest: None.

Source of Funding: This study was funded by University of the Punjab, Lahore, Pakistan.

Ethical approval and consent to participate

The experimental protocols for this study were approved by the ethical committee of College of Pharmacy, University of the Punjab.

\section{References}

Ali JS, Saleem H, Mannan A, Zengin G, Mahomoodally MF, Locatelli M and Zia M, 2020. Metabolic fingerprinting, antioxidant characterization, and enzyme-inhibitory response of Monotheca buxifolia (Falc.) A. DC. extracts. BMC Complement. Med. Ther. 20: 1-313.

Ali JS, Khan I and Zia M, 2020. Antimicrobial, cytotoxic, phytochemical and biological properties of crude extract and solid phase fractions of Monotheca buxifolia. Oriental Pharm. Exp Med. 20: 115-122.

Black M, Mitchell JR, Zimmerman HJ, Ishak KG and Epler GR, 1975. Isoniazid associated hepatitis in 114 patients. Gastroenterol. 69: 289-302.

Bohm BA and Koupai-Abyazani MR, 1994. Flavonoids and Condensed Tannins from Leaves of Hawaiian Vaccinium reticulatum and $V$. calycinum (Ericaceae). Pacific Sci. 48(4): 458463.

Chowdhury A, Santra A, Bhattacharjee K, Ghatak S, Saha DR and Dhali GK, 2006. Mitochondrial oxidative stress and permeability transition in isoniazid and rifampicin induced liver injury in mice. J. Hepatol. 45:117-126.

Gallucci RM, Simeonova PP, Toriumi W and Luster MI, 2000. TNF- $\alpha$ regulates transforming growth factor- $\alpha$ expression in regenerating murine liver and isolated hepatocytes. J. Immunol. 164: 872878.

Hashem MM, Salama MM, Mohammed FF, Tohamy $\mathrm{AF}$ and El-Deeb KS, 2019. Metabolic profile and hepatoprotective effect of Aeschynomene elaphroxylon (Guill. \& Perr.). PLoS One. 14: e0210576.

Jan S, Khan MR, Rashid U and Bokhari J, 2013. Assessment of antioxidant potential, total phenolics and flavonoids of different solvent fractions of Monotheca Buxifolia Fruit. Osong. Public. Health. Res. Perspect. 4: 246-254.

Khan I, Ali JS, Ul-Haq I and Zia M, 2020. Biological and phytochemicals properties of Monotheca buxifolia: An unexplored medicinal plant. Pharm. Chem J. 54: 293-301.

Khan MZ, Shabbir MI, Saqib Z, Gilani SA, Jogezai NU, Kiyani MM and Malik MA, 2020. Investigation of polyphenol profile, antioxidant activity and hepatoprotective potential of Aconogonon lpinum (All.) Schur roots. Open Chem. 18: 516-536. 
Kumarasamy Y, Byres M, Cox PJ, Jaspars M, Nahar $\mathrm{L}$ and Sarker SD, 2007. Screening seeds of some Scottish plants for free-radical scavenging activity. Phytother Res. 21: 615-621.

Mitchell JR, Zimmerman HJ, Ishak KG, Thorgeirsson UP, Timbrell JA, Snodgrass WR and Nelson SD, 1976. Isoniazid liver injury: clinical spectrum, pathology, and probable pathogenesis. Annal. Int. Med. 84: 181-192.

Nwidu LL and Teme RE, 2018. Hot aqueous leaf extract of Lasianthera africana (Icacinaceae) attenuates rifampicin-isoniazid-induced hepatotoxicity. J. Integr. Med. 16: 263-272.

Prince SE, Udhaya LB, Sunitha PS and Arumugam G, 2016. Reparation of isoniazid and rifampicin combinatorial therapy-induced hepatotoxic effects by Bacopa monnieri. Pharmacol. 98(1-2): 29-34.

Rehman J, Khan IU, Farid S, Kamal S and Aslam N, 2013. Phytochemical screening and evaluation of in-vitro antioxidant potential of Monotheca buxifolia. E3. J. Biotechnol. Pharm. Res. 4: 5460.

Slinkard K and Singleton VL, 1977. Total phenol analyses: automation and comparison with manual methods. Am. J. Enol. Viticult. 28: 49-55.

Tahmasebi M, Sadeghi H, Nazem H, Kokhdan EP and Omidifar N, 2018. Hepatoprotective effects of Berberis vulgaris leaf extract on carbon tetrachloride-induced hepatotoxicity in rats. J. Educ. Health. Promot. 7. 147. doi: 10.4103/jehp.jehp_48_17.

Ullah I, Khan JA, Adhikari A and Shahid M, 2016. Hepatoprotective effect of Monotheca buxifolia fruit against antitubercular drugs-induced hepatotoxicity in rats. Bangladesh. J. Pharmacol.
11: $248-256$.

Urrutia-Hernández TA, Santos-López JA, Benedí J, Sánchez-Muniz FJ, Velázquez-González C, la OArciniega D and Bautista M, 2019. Antioxidant and hepatoprotective effects of Croton hypoleucus extract in an induced-necrosis model in rats. Molecules. 24: 2533.

Vinaykumar NM, Mahmood R, Krishna V, Ravishankara B and Shastri SL, 2020. Antioxidant and in vivo hepatoprotective effects of Gardenia gummifera L. fruit methanol extract. Clin. Phytosci. 6: 47.

Vlaisavljević S, Jelača S, Zengin G, Mimica-Dukić N, Berežni S, Miljić M and Stevanović ZD, 2019. Alchemilla vulgaris agg. (Lady's mantle) from Central Balkan: antioxidant, anticancer and enzyme inhibition properties. RSC Adv. 9: 37474-37483.

Zimmerman M, 1983. Ethical guidelines for investigation of experimental pain in conscious animal. Pain. 16: 109-110.

\section{Contribution of Authors}

Javed S: Performed experiments, collected \& analysed data and wrote first draft of the manuscript

Shoaib A: Helped in write up and editing of the manuscript

Mehmood Z: Designed experiment \& helped in data analysis

Ishtiaq S: Performed analgesic and cytotoxic activity assays. 